\title{
Observations of Comet Wolf 1898 IV
}

made at the Lick Observatory of the University of California by William $\mathcal{F}$. ITussey.

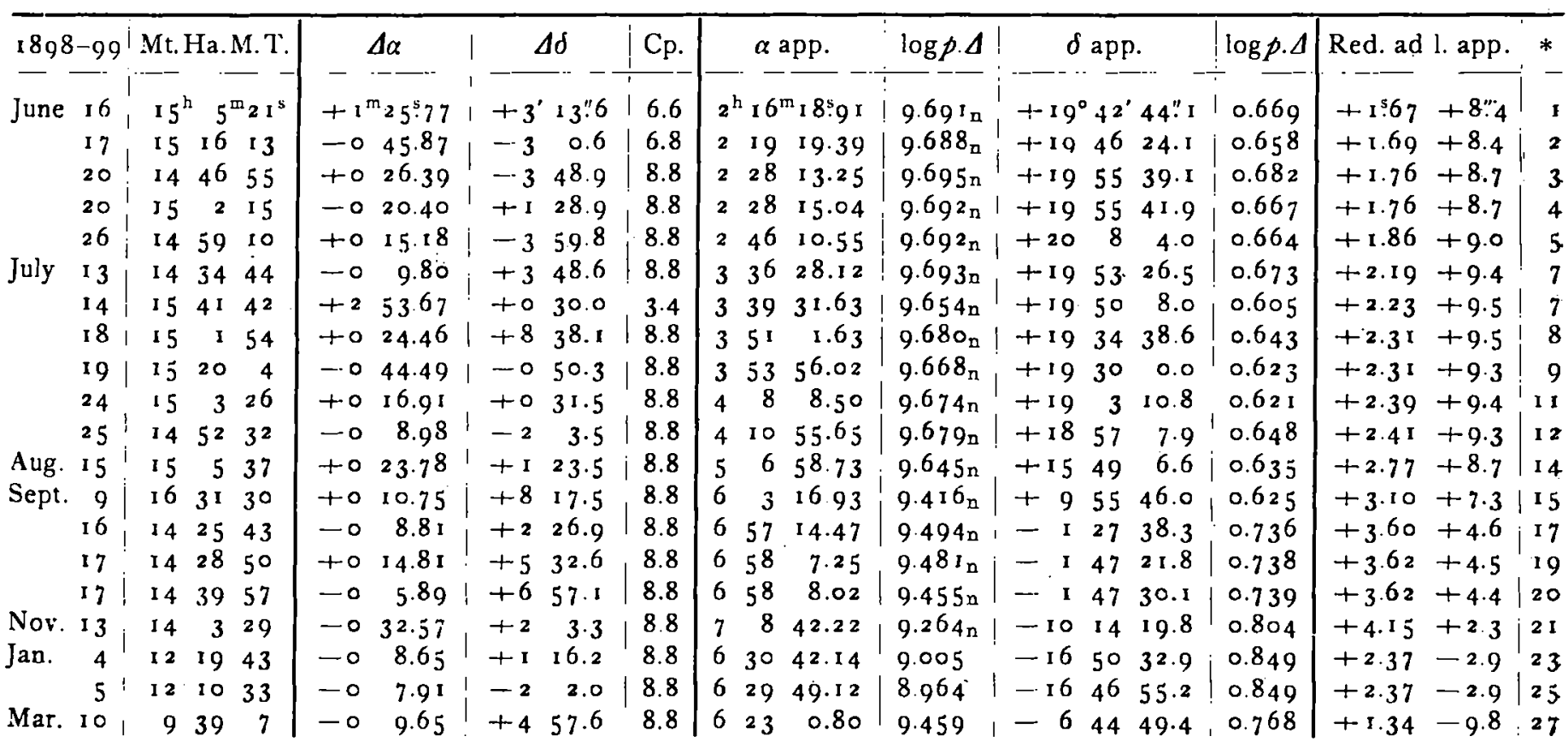

Mean Places for 1898-99.0 of Comparison Stars.

\begin{tabular}{|c|c|c|c|c|c|c|c|}
\hline * & & $\alpha$ & & $\delta$ & & Authority & \\
\hline 1 & & & & & & $--\cdots$ & \\
\hline 1 & & 94 & $+19^{\circ}$ & $39^{\circ}$ & 22 ". 1 & AG. Berlin A. 646 & \\
\hline $21^{2}$ & 20 & $3 \cdot 57$ & +19 & 49 & 16.3 & AG. Berlin A. $67 \mathrm{I}$ & \\
\hline $3 \mid 2$ & 27 & 45.10 & +19 & 59 & $19 \cdot 3$ & AG. Berlin A. 697 & \\
\hline 42 & 28 & 33.68 & + I9 & 54 & $4 \cdot 3$ & AG. Berlin A. 700 & \\
\hline $5 i^{i 2}$ & 45 & $53.5 \mathrm{I}$ & +20 & I I & 54.8 & $101 / 2$ connected with & *6 \\
\hline 6,2 & 48 & $29 \cdot 74$ & +20 & 8 & $59 \cdot 4$ & AG. Berlin A. 780 & \\
\hline 73 & 36 & $35 \cdot 73$ & +19 & 49 & 28.5 & AG. Berlin A. 99 I & \\
\hline & 50 & 34.86 & † I 9 & 25 & 51.0 & AG. Berlin A. I050 & \\
\hline $9 ! 3$ & 54 & 38.20 & +19 & 30 & 41.0 & $9 \frac{1}{2}$ connected with & $* 10$ \\
\hline $10: 3$ & 55 & 34.89 & +19 & $3 \mathrm{I}$ & 27.2 & AG. Berlin A. 1067 & \\
\hline I 14 & 7 & 49.20 & +19 & 2 & 29.9 & AG. Berlin A. I I 12 & \\
\hline $12 \mid 4$ & I I & 2.22 & +18 & 59 & 2. I & ro $1 /{ }^{m}$ connected with & * I 3 \\
\hline I 3 , 4 & I I & $23.5^{8}$ & +19 & 6 & I 3.6 & AG. Berlin A. 1123 & \\
\hline I 4,5 & 6 & 32.18 & +15 & 47 & 34.4 & AG. Berlin A. I 426 & \\
\hline
\end{tabular}

Mt. Hamilton, California, 1899 Aug. 30.

\begin{tabular}{|c|c|c|c|c|c|c|c|}
\hline * & & & $\alpha$ & & $\delta$ & & Authority \\
\hline & & $\begin{array}{l}3^{\text {II }} \\
3\end{array}$ & $\begin{array}{l}3.08 \\
1.12\end{array}$ & $\begin{array}{l}+c \\
+9\end{array}$ & & $\begin{array}{ll}2 & 21.1 \\
8 & 57.4\end{array}$ & $\begin{array}{l}10^{\mathrm{m}} \text { connected with } * 16 \\
W_{1} 5^{\mathrm{h}} \times 566\end{array}$ \\
\hline I 7 & & 57 & 19.68 & -1 & I 30 & 9.8 & $9^{\mathrm{m} 1}$ connected with $*$ i 8 \\
\hline 18 & 6 & 59 & $35.9 \mathrm{I}$ & --1 & I 31 & $1 \quad 11.8$ & Gött $_{1} 23$ I $5-16$ \\
\hline I 9 & 6 & 57 & 48.82 & -- & $5^{2}$ & $5^{8.9}$ & Gött $12299-00$ \\
\hline 20 & 6 & $5^{8}$ & 10.29 & -1 & 54 & $4 \quad 32.2$ & Gött $12303-04$ \\
\hline $2 \mathrm{I}$ & 7 & 9 & 10.64 & --10 & I 6 & $25 \cdot 4$ & $8^{\mathrm{m}} 8$ connected with $* 22$ \\
\hline 22 & 7 & 8 & 42.20 & --10 & 20 & 0.4 & Quet. 3009 \\
\hline 23 & 6 & $3^{\circ}$ & 48.42 & -16 & 51 & 46.2 & I ${ }^{\text {m }}$ connected with $* 24$ \\
\hline 24 & 6 & 33 & I 3.86 & - I 6 & 55 & 31.6 & BB. VI $6^{\mathrm{h}} 110$ \\
\hline 25 & 6 & 29 & 54.66 & -16 & 644 & 50.3 & I $2^{\mathrm{m}}$ connected with $* 26$ \\
\hline 26 & 6 & 34 & $5 \cdot 39$ & -16 & 47 & 2. I & $\operatorname{Rad}_{3}+653$ \\
\hline 27 & 6 & 23 & 9.11 & -6 & 49 & 37.2 & $12^{\mathrm{m}}$ connected with $* 28$ \\
\hline 28 & 6 & 23 & 10.23 & -6 & $5 \mathrm{I}$ & 50.1 & AG. Ottakring \\
\hline
\end{tabular}

William $\mathcal{~}$. Hussey.

\section{Observations of Tuttle's Periodic Comet 1899 III}

made at the Lick Observatory of the University of California by $C$. D. Perrine.

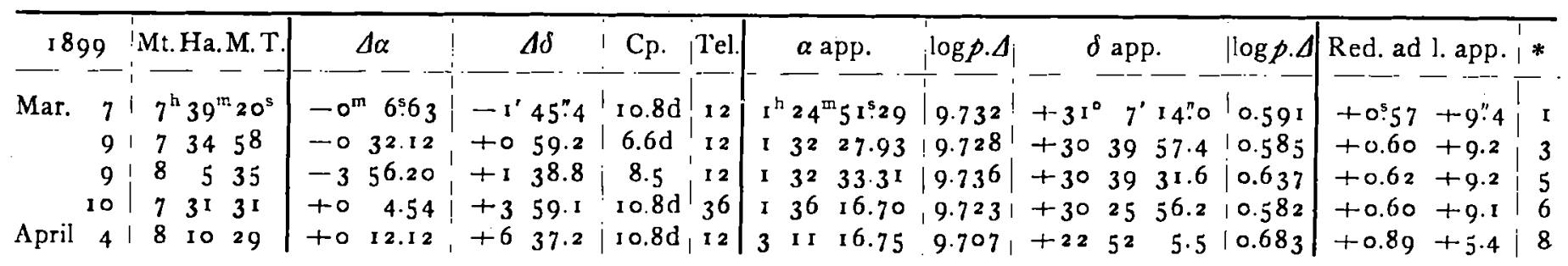

